\title{
DE MAESTROS Y POETAS. EDUCACIÓN Y ARTE EN NIETZSCHE Y RANCIÈRE
}

\author{
Leonardo Javier Colella*
}

\begin{abstract}
RESUMEN
El presente artículo se propone poner en diálogo la noción de "maestro" en Nietzsche y Rancière. Intenta, a través de las figuras de Zaratustra y Jacotot, repensar los problemas elementales, sobre todo aquellos que adquieren presencia a partir de la Ilustración, surgidos a raíz del encuentro entre la filosofía y la educación. Asimismo, busca reconstruir la idea de "Zwischen" en el ámbito educativo y vincularla con la dimensión artística como potencia creadora.
\end{abstract}

Palabras clave: Educación. Arte. Zwischen.

\begin{abstract}
The aim of this paper is to put in dialogue the notion of "teacher" in Nietzsche and Rancière. It proposes, through the figures of Jacotot and Zarathustra, rethink the elementary problems, especially those who acquire presence in the Enlightenment, arisen as a result of the encounter between philosophy and education. It also seeks to reconstruct the idea of "Zwischen" in education and link it with the artistic dimension as a creative power.
\end{abstract}

Keywords: Education. Art. Zwischen.

\footnotetext{
* Profesor Universitario de Filosofía por la Universidad Nacional de General Sarmiento (UNGS). Consejo Nacional Científico y Técnico (CONICET).E-mail: leonardojcolella@, yahoo.com.ar
} 


\section{De maestros y de artistas}

Tal vez exista un enigma que conmovió por igual las noches de Nietzsche y de Jacotot: ¿para qué enseñar y aprender sobre sueños, sabiendo que son sueños? El maestro-Zaratustra y el maestro-Jacotot se apartan de la figura del tradicional maestro de la sabiduría, el primero enseña a no asumir ningún saber como seguro, el segundo enseña a través de su ignorancia. Zaratustra enseña a ser "perdido", Jacotot proclama que se puede enseñar lo que uno no conoce, ambos transmiten lo que no poseen, pero ambos son maestros porque "enseñan".

Sueños en Nietzsche, porque en él los signos abandonan el sentido representacionista, pues nada hay que representar luego de la muerte de Dios. Sobre la nada heredada del León, se erige el niño creador, el artista. El arte permite seguir soñando, sabiendo que se sueña. Y es que para Jacotière $^{1}$, si es posible soñar con una comunidad de emancipados, ella "sería una sociedad de artistas" (RANCIÈRE, 1987, p. 95).

Sueños en Jacotot, porque él describe la imposibilidad de decir y traducir lo que se siente, y siempre está obligado a corregir lo que acaba de insinuar, y esa corrección tampoco le alcanza, ni la siguiente, razón que lo obliga a asumir una perpetua improvisación. E improvisar es la gran virtud poética. El artista narra las aventuras de su espíritu para que sean adivinadas por otros aventureros: la palabra vuela de voluntad a voluntad e intenta la comunicación de "todos estos soñadores entre sí" (NIETZSCHE, 1990, p. 45). El artista sabe de la imposibilidad de decir la verdad, pero sigue soñando, poetizando. Y es que Nietzsche sabe que "el pasado de todos los seres sensibles continúa poetizando en mí” (NIETZSCHE, 1990, p. 46).

\section{Las transformaciones del espíritu educativo}

“Tres transformaciones del espíritu os menciono: cómo el espíritu se convierte en camello, y el camello en león, y el león, por fin, en niño” (NIETZSCHE, 2007, p. 49). Nietzsche ofrece un esquema metafórico que

\footnotetext{
1 El término Jacotière será utilizado para referir a aquellos conceptos, pasajes o ideas en los que la voz de Jacotot y de Rancière se funden y su distinción se torna algo ambigua.
} 
permitiría explorar realidades muy diversas, nos narra las transformaciones del espíritu que ilustrarían diferentes formas de nihilismo. Sirviéndonos de estos signos, podríamos destacar tres momentos en la concepción de diversos modelos o formas de enseñanza.

El camello es la figura del espíritu cuya principal función es el traslado de cargas. Se arrodilla para ser cargado y se dispone a transportar la carga a través del desierto. El educador-camello se nutre de la carga del saber y su tarea fundamental radica en transmitir esos saberes. No se involucra en el contenido de la encomienda, es él mismo un transporte, tan sólo el tránsito, el medio donde se reproducen las ideas y los valores siempre fijos e inamovibles, por tanto, incuestionables. El viejo camello no sabe que ignora. El mundo, para él, está asentado sobre fundamentos cognoscibles, y al no presentársele ningún vacío, ninguna carencia, suprime toda búsqueda creativa. Sólo queda explicar la ciencia, transmitir un saber ya elaborado. El modelo del nihilismo decadente ${ }^{2}$ prescinde de toda exploración novedosa. De este modo, ambiciona sacar al estudiante de su camino para incorporarlo al único camino transitable y así lograr la unidad con el Saber. El educador-camello, tal vez sin saberlo, proyecta el sacrificio de su aprendiz ${ }^{3}$ a través de la pedagogía de la imitación de los modelos.

El método de la mímesis de la estatua-modelo suprime la dimensión creativa de la esfera de la educación, asegurando la continuidad del circuito reproductor. Con todo, Zaratustra advierte a sus propios discípulos: “¿qué ocurrirá si un día vuestra veneración se derrumba? ¡Cuidad de que no os aplaste una estatua!” (NIETZSCHE, 2007, p. 122). La pluralidad de "estatuas-modelos", aun en el caso de la diferencia más acentuada que pueda haber entre ellas, esconde un rasgo común: lo pretérito. Si bien el pasado por sí mismo no impide la novedad, cuando la educación asume la forma de una transferencia unilateral de la tradición a través de un escenario estructurado entre quienes enseñan y quienes aprenden, afirmaremos que

2 Puede encontrarse un amplio desarrollo sobre los conceptos de "nihilismo decadente", "nihilismo integral" y "nihilismo futuro" en Cragnolini (2003).

3 Podría hallarse cierta analogía con la noción de Kénosis como vaciamiento que Cristo hace de sí mismo por obediencia al Padre, y trazarse una referencia al mito de Abraham (KRISTEVA, 2005). 
la educación se constituye así en una compleja estructura de repetición y continuidad: un lugar en donde los muertos sepultan a los vivos. Aquí se ubica el profesor que asume un rol técnico de simple instructor o transmisor, y que se limita a llevar a la práctica los diseños, las formas y contenidos elaborados por otros.

Relata Nietzsche que, mientras Zaratustra dormía, una oveja se acercó a comer de la corona de hiedra que llevaba en su cabeza. La oveja, antes de marcharse, exclamó: "Zaratustra ha dejado de ser un docto" (NIETZSCHE, 2007, p. 185). Como han señalado algunos analistas de la obra nietzscheana, la figura de la oveja, a través de esa expresión, ostenta la potestad de decretar la admisión o la remoción de la membresía de la comunidad de los doctos. En este sentido, la imagen de la oveja representaría a ciertos catedráticos universitarios que rechazaron El nacimiento de la tragedia, obra inicial del propio Nietzsche.

Las instituciones educativas precisan de tal rebaño de ovejas y de sus parámetros legitimadores. Su tarea fundamental es validar determinados criterios de éxito educativo y rechazar otros. Estas pautas específicas que deben cumplirse para que el estudiante "triunfe" en el ámbito de la educación conforman el circuito que denominamos "corona de laureles", en llana oposición a la "corona de hiedra" que, como Dionisos, exhibía Zaratustra (COLELLA, 2012a). La corona de laureles fue reservada históricamente para los grandes atletas, estrategas militares y doctos. Genéricamente, simboliza una recompensa al desempeño exitoso en un circuito dominado a través de reglas instituidas por el poder. La corona de hiedra, en cambio, asume un rango menor. Su conquista radica, paradójicamente, en una perpetua reconfiguración del significado de la "conquista". La naturaleza de la hiedra consiste en poner en cuestión el propio juego y sus reglas, por lo que desvanece toda posibilidad de triunfo $o$ fracaso en el sentido antes dado.

El maestro tradicional, representado en la figura del Sócrates de Nietzsche y de Rancière, encuentra su lugar en la era dogmática del esquema de enseñanzas. Pero en lo más solitario del desierto, nos relata Nietzsche, tiene lugar una segunda transformación: la enseñanza asume la máscara del león. El "tú debes" del camello confronta con el "yo quiero" 
del león. Éste ingresa a la escena con el fin de destruir el viejo modelo, las viejas tablas. Su tarea es la de conquistar libertad, por ello aniquila todo vestigio de construcción pasada. La enseñanza adquiere así un perfil de escepticismo radical: es la etapa del nihilismo integral. Se trata, sin más, de derrocar las arkhaí pedagógicas. El león comienza una tarea que él mismo no puede prolongar. Ha empeñado todo su esfuerzo en la "destrucción", y es en ese vacío, que el universo productivo intenta gradualmente apropiarse del sentido de lo educativo.

\section{La pugna por el sentido: escuela y producción.}

En Sobre el porvenir de nuestros institutos de enseñanza, Nietzsche realiza una crítica al sistema de enseñanza gobernado por dos tendencias: la erudición generalizada de la ilustración y la erudición más restringida de los especialistas. Ambas tendencias serían perniciosas en la medida que reproducen los procesos del universo productivo en el ámbito de la cultura y guían la enseñanza a través de los tiempos y criterios de utilidad de un esquema que determina cuantitativamente el saber necesario para la fabricación de los "doctos". Asimismo, Nietzsche caracteriza a las instituciones educativas como aparatos reproductores que interrumpen el pensamiento: una sola boca que habla para muchos oidos y la mitad de manos que copian. La institución universitaria es definida como el ámbito de agotamiento del pensamiento, el lugar de clasificación y evaluación de los individuos, el cálculo y la categorización de las producciones, el espacio donde el aspecto creativo se vuelve número.

En el mismo sentido, Fitzsimons señala que si bien Nietzsche repara en la función social y económica de las instituciones educativas, se manifiesta contra la idea de que éstas estén limitadas por un propósito únicamente instrumental (FITZSIMONS, 2007). Bachelard retoma la idea griega de scholé como un espacio-tiempo de ocio extraído del universo productivo. Según esta perspectiva, convertir la escuela en una propedéutica para la vida profesional, económica y social sería traicionar el sentido atribuido a la educación desde la filosofía clásica y, sobre todo, desde la Ilustración: esto sería, traicionar una educación cuyo sentido sea la “emancipación intelectual” (FABRE, 2003). 
Para Rancière, la scholé no es definida por una finalidad social externa, sino que asume la fisonomía de una forma simbólica que, precisamente, establece una separación con los tiempos, espacios y ocupaciones sociales (RANCIÈRE, 1988). La forma-escuela asume una particular distribución de los tiempos, ya que no se constituye en el lugar exclusivo para la comercialización de una ciencia útil para la vida productiva, sino que, más bien, es definida principalmente por la figura del ocio. La scholé separa dos usos del tiempo: el que se utiliza forzadamente para la producción y el que se dispone libremente al estar dispensado de las exigencias del trabajo. Por ello, la scholé griega delimitaba el modo de vida de los iguales, hacía de los escolares de la Academia o del Liceo los iguales por excelencia.

Así, la forma-escuela tomaría distancia con respecto a las necesidades del universo laboral y a la transmisión de contenidos proveedores de herramientas útiles para la vida productiva. En este sentido, este aspecto formal que Rancière destaca de la scholé desestimaría la hipótesis de la escuela como una institución de distribución de las ciencias cuya finalidad sería la justa distribución de los lugares sociales. En contraposición a ello, la forma-escuela constituiría un posible escenario de igualdad al relegar a los "escolares" del mundo social desigual e incluirlos en el mismo tiempo de ocio. La escuela, para Rancière, no sería el lugar de promoción de una ciencia útil para la vida en sociedad, sino más bien, un espacio privilegiado para la verificación de la igualdad, y por lo tanto, sus eventuales consecuencias transformadoras irrumpirían de la distancia que disponga con respecto a la lógica del universo productivo.

\section{La lección de Nietzsche}

Nietzsche inaugura una línea crítica con respecto a la concepción moderna de "sujeto" y "representación". La postulación de la muerte de Dios deriva en consecuencias gnoseológicas, ya que toda "traducción" de orden ontológico deviene una "traición" en el plano de la representación. 
Nietzsche, en Sobre verdad y mentira en sentido extramoral, sostiene que los conceptos son metáforas no asumidos como metáforas, idea que Derrida enuncia como "mitología blanca", aludiendo al olvido por parte del lenguaje de su género metafórico (CRAGNOLINI, 2010). En el ámbito de la educación, esta perspectiva denuncia la transmisión de conocimientos o habilidades que se pretenden garantes del dominio de lo real mediante una apropiación del sentido.

En tal aspecto, Nietzsche también elabora una crítica contra la noción de Bildung. La concepción de hombre del humanismo, como ideal a ser realizado, es puesta en cuestión por la filosofía nietzscheana (CRAGNOLINI, 2005). La figura de Dioniso en Nietzsche asume la postura de anti-Bildung, desestimando una idea previa de hombre, que pueda ser cultivada o "formada" mediante determinados valores o saberes. De allí que Deleuze sostenga la idea de "desprenderse" de toda figura esencial y constitutiva de lo humano. La función de "formar" supondría una "forma" previa ya delimitada según una concepción teleológica de la humanidad.

No obstante, la figura del maestro en Nietzsche busca "desprenderse" de su sabiduría y no transmitirla como una propiedad destinada a la lógica del intercambio. Nietzsche asocia al docto de la Bildung con el hombre de mercado, que en el acto del "intercambio" se afirma a sí mismo y a sus propiedades. El maestro nietzscheano se contrapone a la figura del erudito ya que no se propone como donador de propiedades (conocimientos, valores, etc.), sino que rompe con la lógica del cálculo a través de la desposesión de un pensar seguro, del juego de conceptos, de la dispersión de sentidos que asume afirmativamente en contraposición a la economía de los saberes legítimos y sofisticados. La diseminación de sentidos rompe con la lógica de producción y resultados que guía el esquema de productividad de las instituciones educativas. El maestro en Nietzsche no transmite ningún saber particular, sino que enseña a no asumir ningún saber como sagrado, ningún valor como cierto, ningún concepto como seguro; en este sentido, enseña a poner en cuestión el tono dogmático de la enseñanza. A la par de Jacotière, la filosofía nietzscheana establece su crítica contra el maestro de la sabiduría en oposición al maestro ignorante. 


\section{EI rayo Jacotot}

Para continuar la tarea del león destructor, afirma Nietzsche, es preciso la figura del niño, que es olvido y nuevo comienzo: con él asistimos al juego de la creación. El niño-educador, el maestro-artista, asume la tarea de construir sobre las ruinas heredadas del león. Interrumpe, de forma creativa, la reproducción de saberes instituidos. Invita a repensar la lógica de esas continuidades y a cuestionar los saberes prefigurados y establecidos. El educador-artista es antidogmático por excelencia, asume siempre posiciones provisorias. No acepta el juego oficial, está siempre proponiendo un nuevo juego. Para Nietzsche la figura del artista se contrapone a la del docto. El educador artista juega con los conceptos, asume los riesgos de un pensar incierto que se erige más allá de los resultados.

Jacotot, a su manera, anunció la muerte de Dios en contra del vizconde de Bonald cuando desechó la existencia de una ley divina que unificaba las leyes de la lengua, las leyes de la sociedad y las del pensamiento. El pensamiento se traduce para un otro, que a la vez conformará un nuevo relato: una voluntad que quiere comunicar y otra que desea adivinar lo que la primera ha pensado y sentido, y que para ello debe ser capaz ella misma de poetizar. La imposibilidad de una "traducción" plena hace del decir una improvisación incesante, convirtiendo a Jacotot en un maestropoeta: creador de figuras, palabras, metáforas, etc., semejante a esa madre que abraza a su hijo luego de una larga y cruenta guerra. Paralizada por el reencuentro, no puede decir nada, no tiene palabras, pero la asfixia de sus manos sobre la espalda de su hijo no sólo habla el espontáneo lenguaje del amor sino también el idioma temeroso por volver a separarse y a perderse; su sonrisa corrige el código de sus lágrimas que enfatiza la alegría del reencuentro tras la impotencia de no haber evitado la distancia o tal vez esa y todas las guerras. Toda esa improvisación, se interroga Jacotière, ¿no es el más elocuente de los poemas?

El educador-artista no transmite su conocimiento sino que poetiza, traduce e invita a otros a practicar ese arte. Rancière hace de Jacotot el rayo que parte los fundamentos de la educación moderna: el sentido de la educación no sería intentar reducir la desigualdad de conocimientos entre maestro y alumno a través del método explicativo, sino verificar 
la igualdad de la potencia poética de las voluntades que juegan en un encuentro educativo.

El maestro de la sabiduría no quiere decir nada, quiere oídos que escuchen y manos que escriban. Busca sobrevalorar sus posesiones, de ahí la dosificación y la gradualidad de su transmisión. Especula seguir siendo, para siempre, el maestro. Y por ello tiene la necesidad de reproducir la distancia entre una sabiduría y otra, necesita la subordinación de una inteligencia a otra. El educador artista, en cambio, sabe que todo acto de traducción requiere una contratraducción, y que todo poema es la ausencia de otro poema. Por eso sabe que cualquiera puede poetizar, sólo basta, una vez más, una voluntad que quiera comunicar y otra que quiera adivinar, y viceversa. El vínculo propuesto por Jacotot se sostiene en una igualdad por esta sencilla razón: sabe que cualquiera, además del maestro, puede poetizar y adivinar el abrazo de una madre o la furia silenciosa de un amante. Aunque el lenguaje no pueda decirlo todo, el artista confía en la voluntad creativa que intenta una palabra, una figura, y que a la vez pueda ser descifrada, sin que haya seguridad en el tránsito de la boca al oído, pretensión ésta del maestro-sabio.

Rancière opone la función embrutecedora del profesor a la tarea emancipadora del artista. Cualquiera que ante la experimentación o la práctica de un oficio busque expresarse o comunicarse asume, de alguna manera, una tarea artística. Y para ello debe suponer que cualquier "otro" podrá comprenderlo, que cualquiera es capaz de traducir, contratraducir, poetizar y adivinar. El maestro-artista precisa de la igualdad tanto como el maestro-explicador necesita de la desigualdad.

\section{Sobre enseñar lo que no se tiene}

El sujeto, en Nietzsche, asume identidades provisorias, densidades variables de fuerzas, que se constituyen "entre" sus otras máscaras y la de los otros. El otro es parte constitutiva de su identidad provisoria. A diferencia del sujeto moderno, el sujeto escindido, al constituirse en el "entre" (Zwischen) ${ }^{4}$, está constantemente desapropiándose de sí mismo y

4 Un desarrollo en profundidad del concepto de Zwischen puede hallarse en Cragnolini, 2006. 
aceptando la imposibilidad de un dominio integral de la realidad, de su diáfana traducción, de su explicación y transferencia.

Muchas "almas" habitan en el cuerpo, que de este modo siempre es un cuerpo im-propio, en cuanto en él están presentes las otras "máscaras" del sí-mismo y de la alteridad. Abandonado el escenario moderno de las conciencias enfrentadas, el "otro", la alteridad, ya está presente en la mismidad. La noción de Selbst, contrapuesta a la de Ich cartesiano, permite pensar en la posibilidad de un sujeto múltiple, en el que la ficción de la identidad es concebida como juego constante y provisorio de estructuración y desestructuración. En la consideración nietzscheana del sujeto como Zwischen, el encuentro con el otro no es pensado según el modelo moderno de dos entidades (dos sujetos, dos conciencias) que se enfrentan.

Para Nietzsche, el hombre es caos, multiplicidad, azar. No existe propietario alguno de nada, ni de sus atributos, ni del mundo (transformado en objeto de conocimiento), ni de los otros. La figura del ultrahombre propuesta por Nietzsche, cuyo rasgo distintivo es la desapropiación y el desprendimiento, concibe el amor a través del don (CRAGNOLINI, 2006). Ya no como un ofrecimiento que instituye una deuda, sino como una entrega que no espera nada a cambio. En la misma donación se suprime la exigencia de la devolución al tiempo que se acepta la diferencia. El ultrahombre se entrega él mismo en el amor, pero paradójicamente eso que entrega ni siquiera es suyo, no se posee a sí mismo y tampoco tiene nada para dar en términos de propiedad, pues ha aceptado que hay cosas que escapan a su dominio.

En Éloge de l'amour, Alain Badiou (2009) plantea la constitución de un sujeto amoroso a partir del encuentro contingente y azaroso entre individuos, la construcción de un nuevo mundo desde un punto de vista descentrado respecto de uno mismo, la experiencia de ese mundo a partir de la diferencia y no únicamente de la identidad. En el amor, Badiou afirma que existiría la experiencia del desborde de la singularidad pura, proceso que va desde lo particular de un encuentro hasta la experiencia de un mundo habitado desde la diferencia y no sólo desde la uniformidad.

El amor, para Badiou, es la posibilidad de una nueva vivencia del mundo experimentado a partir de lo Dos, de la diferencia; es la prueba de que el mundo puede ser vivido de otro modo que mediante una conciencia 
individual. Lo universal en el amor consistiría en la experimentación de lo que es ser Dos. Este amor en el escenario de la educación nos permitiría indagar sobre la posibilidad de una experiencia del "pensar", del "decir", del poetizar, desde un punto de vista descentrado de uno mismo, y ya no como una mera transmisión o un simple intercambio de contenidos objetivos entre conciencias enfrentadas.

Zaratustra y Jacotot educan con amor, ambos enseñan lo que no poseen. Sin embargo, ni uno ni otro prescinden de la figura del maestro. Se entregan ambos, se ofrecen sabiendo que no se poseen ni poseen algo para transferir. Pero una vez que comprenden que nada poseen, descubren los sueños, y el juego de todos estos soñadores entre sí. Entonces inventan figuras, poetizan, y lo hacen enseñando que ningún alma dogmática y desatenta podrá jugar el juego de los artistas, pero que cualquier voluntad que quiera adivinar y poetizar podrá hacerlo: una educación para todos y para nadie. Ambos preferirían ser prescindibles, ambos aspiran a ser "perdidos" alguna vez. Ambos buscan emancipar(se), porque si podemos soñar con una comunidad de emancipados, afirma Jacotière, esa sería una sociedad de artistas.

\section{De silencios y melodías}

La educación del camello es la del traslado de cargas. El viejo camello debe transportar los saberes y valores preestablecidos a las nuevas generaciones. Las instituciones educativas asumen una función reproductora. Recogen los conocimientos desde una esfera exterior a sí misma, desde otros campos en los que son fabricados, y los transmiten en su interior como saberes instituidos. El acto creativo, propio del artista, es relegado por fuera del aparato educativo.

La Ilustración proclamaba una educación para la libertad y la emancipación, y al mismo tiempo, le atribuía una función destacada en la gobernabilidad de los sujetos, la reproducción del lazo social y la formación de las naciones. Fue allí cuando un pedagogo revolucionario hizo oír su voz disonante: no se trataría de reducir la desigualdad entre los conocimientos de uno y otro individuo mediante la instrucción del pueblo, sino de actualizar la igualdad de la potencia poética del decir y del 
pensar de todos los hombres. El mundo de la ilustración tuvo que oírlo. La conmoción fue más allá de Lovaina, Bruselas y La Haya, atravesó París y Lyon, se expandió por Europa hacia el norte y hacia el este, lo oyeron en Inglaterra y en Prusia, traspasó al imperio ruso y sus ecos alcanzaron el continente americano. Durante dos décadas, la República del Saber sufrió un cimbronazo en sus raíces al momento de su propia fundación. Pero para mediados del siglo XIX, la fuerza de la industria, la República, el derecho, la opinión pública y la prensa demandaron un método expeditivo de instrucción de las masas: la explicación. Y así el progresismo ilustrado reactivó el viejo principio de la desigualdad de las inteligencias. De este modo, la voz de Jacotot fue perdiendo vigor, hasta apagarse y volverse, progresivamente, silencio.

El león es la figura que representa la destrucción de los viejos fundamentos educativos. Deja en evidencia el sinsentido de una educación que nace paradójica. El león desnuda los supuestos pedagógicos y con ellos sus propias contradicciones. La fuerza del mercado busca instalarse en ese vacío. Actualmente, la educación se constituye en la ficción distributiva del orden social (COLELLA, 2012b). Obedece a la lógica utilitarista del intercambio, fija los criterios meritocráticos de segmentación de lugares y posiciones.

El león-Nietzsche prorrumpe para intentar una nueva arremetida. Jacotot reanima sus postulados, ahora bajo la pluma de Rancière. El león precisa del niño creador, del artista. El maestro-poeta asume que no es posible una traducción plena y completa: los poetas sueñan demasiado. Traduce lo que siente, lo que imagina, lo que piensa. Improvisa, poetiza: una voluntad artística que confía en otra voluntad que, como ella, adivine, traduzca y poetice. El método explicativo del Viejo requiere una inteligencia inferior a otra, una sabiduría superior a otra. La voluntad del artista, en cambio, necesita fundar su vínculo en la igualdad de la potencia poética.

Considerar la unidad "docente" o la unidad "alumno" como sujeto pedagógico hace fluctuar los análisis educativos entre los modelos de la "imitación" o de la "experimentación": se trata, por un lado, de la clásica mímesis del docente-modelo que opera a favor de la reproducción y que fue denunciada como autoritaria desde la Escuela Nueva; y por el otro, de la más novedosa experimentación del estudiante por sí mismo (con 
mayor o menor "guía" del profesor) que acepta pasiva una postergación de la intervención creativa (prórroga indefinida durante el aprendizaje en nombre de una experimentación siempre inacabada).

De una u otra manera, el sujeto de la explicación supone una conciencia propietaria en busca de otra subsumida a la lógica del intercambio. Por el contrario, podría pensarse que el sujeto de la educación artística es el encuentro de las voluntades desapropiadas que intentan verificar la igualdad de una potencia creativa común: tal vez para eso sea necesario enseñar y aprender sueños, aun sabiendo que son sueños. También por ello el sujeto educativo se halla en el Zwischen, porque no es una ni otra unidad, sino la multiplicidad del encuentro.

La lección del artista no se manifiesta aquí de otro modo más que como la lección de este encuentro: el de un pedagogo revolucionario, un filósofo artista y un "vagabundo" husmeador de archivos de sueños obreros (un contrapunto filosófico-educativo tal vez resistido por criterios académicos). Voces disonantes para el tempo de sus tiempos. Quizá puedan volver a ser arrancadas durante siglos por el más tenaz de los silencios. Pero ellos saben que mientras haya filósofos y artistas, la melodía alguna vez volverá a soñar.

\section{Referências}

BADIOU, A. Éloge de l'amour. Paris: Flammarion, 2009.

COLELLA, L. Foucault y Rancière como educadores. La explicación como técnica de sí mismo. Revista Sul-Americana de Filosofía e Educação, Brasília, v. 1, n 18, p. 162-172, mai./out. 2012.

COLELLA, L. Las coronas de la educación. Subjetividad y reproducción en las instituciones educativas. Revista Paideia, Madri, v. 32, n. 95, p. 281288, set./dez. 2012a.

CRAGNOLINI, M. Estranhos ensinamentos: Nietzsche-Deleuze. Educação \& Sociedade, Campinas, v. 26, n. 93, p. 1195-1203. 2005.

. Moradas Nietzscheanas. Del sí mismo, del otro y del "entre". Buenos Aires: La Cebra, 2006.

. Nietzsche, camino y demora. Buenos Aires: Biblos, 2003. 
. Una (im)posible educación postnietzscheana. In: ENCUENTRO INTERNACIONAL GIROS TEÓRICOS. FRONTERAS Y PERSPECTIVAS DEL CONOCIMIENTO TRANSDISCIPLINARIO, 3., 2010, Buenos Aires. Actas... Buenos Aires: [s.n.], 2010.

FABRE, M. ¿Qué es la filosofía de la educación? In: HOUSSAYE, Jean. (Comp.). Educación y filosofía. Enfoques contemporáneos. Buenos Aires: Eudeba, 2003.

FITZSIMONS, P. Nietzsche, ethics and education. An account of difference. Rotterdam: Taipei, 2007.

KRISTEVA, J. Travesía de los signos. Buenos Aires: La Aurora, 1985.

NIETZSCHE, F. Asi habló Zaratustra. Buenos Aires: Alianza Editorial, 2007.

. La conciencia de la apariencia. In: . La ciencia jovial. La gaya scienza. Caracas: Monte Ávila, 1990. RANCIÈRE, J. Ecole, production, égalité. In: . L'école de la démocratie. Edilig: Fondation Diderot, 1988. . Le maître ignorant. Cinq leçons sur l'émancipation intellectuelle. París: Fayard, 1987.

Data de registro: $27 / 06 / 2013$

Data de aceite: 18/09/2013 